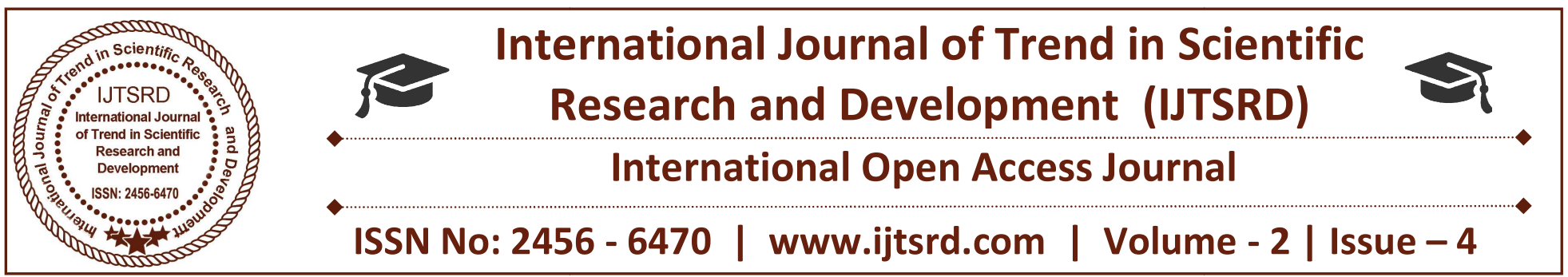

\title{
Nosocomial Infections in Pediatric Intensive Care Unit
}

\author{
Sayali Daptardar \\ Assistant Professor, Department of Microbiology \& Biotechnology, VPM's B N Bandodkar College, \\ Thane, Maharashtra, India
}

\begin{abstract}
Hospital acquired infection is one of the ignored causes that burden the developing country like India economically. The present prospective study was carried out in the Pediatric Intensive Care Unit (PICU) of a tertiary care teaching hospital in Mumbai. As intensive care units pose patients to higher risk of infection, they need more attention in view of reducing hospital acquired infections. This study was undertaken to determine the incidence rate, risk factors and organisms responsible for nosocomial infections along with antimicrobial sensitivity patterns of the pathogens. Among all the positive isolates two isolates were found to be multi drug resistant. The infection pattern was analyzed based on the different criteria viz. age of the patient, stay in ICU in terms of number of days and gender of the patient, to understand their roles in incidence of infection. The study intends to throw light upon the increasing incidences of nosocomial infections in hospitals and increase awareness among society to follow simple precautionary measures to avoid the loss.
\end{abstract}

Keywords: Nosocomial infections, Pediatric, Intensive Care Units

\section{INTRODUCTION:}

Nosocomial infections are always secondary to the patient's original condition for which they are admitted to the hospital. They are also referred to as iatrogenic infections by hospital staff. Intensive Care Units (ICUs) are considered as high risk areas as they admit critically ill patients who are more susceptible to develop infections [13]. The risk of infection varies with the type of ICU. The type of pathogen also varies

with infection site. Nosocomial infections in the pediatric intensive care unit have been a significant source of morbidity and mortality. The higher risk of pediatric patients is due to immunocompromised state in childhood. The patients admitted to pediatric intensive care units are of variety of infections. They lack separation walls between the beds which increase the chances of acquiring nosocomial infections even more. One of the earliest records of hospital infections are perhaps those found in an Egyptian papyrus written around 3000 B.C. Needless to say, mere absence of documentation of bacterial infection does not exclude its prevalence prior to this time. Looking at the increasing share of the nosocomial infections in pediatric mortality all over the world it is imperative to conduct timely studies for finding out their source and uprooting their causes to prevent any relapse of cases.

\section{MATERIALS AND METHODS:}

\section{Sample Collection}

All newly admitted patients during the study period were considered, to study the incidence rate of nosocomial infections in Pediatric Intensive Care Unit. Appropriate samples from the patients were collected at regular time intervals. These samples included blood, endotracheal aspirate, cerebrospinal fluid (CSF), urine and pus (if any infection is detected).

\section{Isolation of Organisms:}

These samples were used to streak isolate on different microbiological media viz. Blood agar, MacConkey’s 
agar, Chocolate agar, Nutrient agar. Bacterial colonies of pathogenic organisms were primarily focussed in the current study.

\section{Identification of organisms:}

Different biochemical tests were used to identify the organisms up to species level. The biochemical tests for gram positive isolates included included catalase, coagulase, nitratase, bile solubility, urease and sugar fermentation tests. $6.5 \% \mathrm{NaCl}$ and Bile Esculin were the additional tests for suspected Group D Streptococci. Gram negative isolates were also tested for oxidase, IMViC (Indole, Methyle Red, Vogus Prauskeur, Citrate) \& Triple sugar Iron (TSI). Organisms were identified according to the Bergey's Manual of Systemic and Determinative Bacteriology. Nosocomial Infections were confirmed based upon patients' clinical data.

\section{Antibiotic Sensitivity Testing:}

Isolated organisms were then studied for their sensitivity to antibiotics. Antibiotic susceptibility was determined using the Kirby-Bauer method and the results were interpreted as per National Committee for Clinical Laboratory Standards guidelines ${ }^{[10]}$.

\section{Analysis:}

Results were noted and analyzed. The analysis also included finding out correlation of incidence of the nosocomial infections with the age and gender of the patient and ICU stay in terms of number of days.

\section{RESULTS:}

A total of 150 patients were studied. The patients of age group up to twelve years were included in the study. Different samples of the patients were processed and were studied for isolation of organisms causing nosocomial infections. (Table 1)

Table 1: Specimenwise Distribution of Organisms

\begin{tabular}{|c|c|c|c|c|c|c|c|c|c|c|c|c|c|}
\hline Specimen & Processed & Positive & Sa & Sp & Ef & Ec & $\mathbf{A b}$ & Kp & $\mathbf{P a}$ & $\mathbf{P v}$ & $\mathbf{S t}$ & $\mathbf{C k}$ & $\mathbf{C a}$ \\
\hline Blood & $\mathrm{O}$ & 15 & 03 & 03 & 01 & & 02 & 01 & 01 & & - & - & 04 \\
\hline ET & & 25 & - & 03 & 03 & 03 & 04 & 06 & 05 & - & - & - & 01 \\
\hline Urine & & 12 & - & - & 04 & 03 & - & 01 & 01 & - & - & 01 & 02 \\
\hline Ear & & 01 & -1 & $2-4$ & $6=$ & 7 & - & - & 01 & - & - & 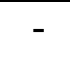 & - \\
\hline Pus & & 03 & 01 & - & - & 01 & - & - & 01 & - & - & - & - \\
\hline Tot & & 56 & 04 & 06 & 08 & 07 & 06 & 08 & 09 & - & - & 01 & 07 \\
\hline
\end{tabular}

ET: Endotracheal aspirate

Sa: Staphylococcus aureus

Sp: Streptococcus pyogens

Ef: Enterococcus faecalis

Ec: Escherichia coli

Ab: Acinetobacter baumanii
Kp: Klebsiella pneumonia

Pa: Pseudomonas aeruginosa

Pv: Proteus vulgaris

St: Salmonella typhi

Ck: Citrobacter koseri

Ca: Candida albicans 


\begin{tabular}{|r|l|}
\hline & Name of the organisms \\
\hline 1 & Enterococcus faecalis \\
\hline 2 & Streptococcus pyogenes \\
\hline 3 & Streptococcus pneumoniae \\
\hline 4 & Staphylococcus aureus \\
\hline 5 & Klebsiellapneumoniae \\
\hline 6 & Pseudomonas aeruginosa \\
\hline 7 & Escherichia coli \\
\hline 8 & Acinetobacter baumannii \\
\hline 9 & Candida spp. \\
\hline 10 & Citrobacter Koseri \\
\hline
\end{tabular}

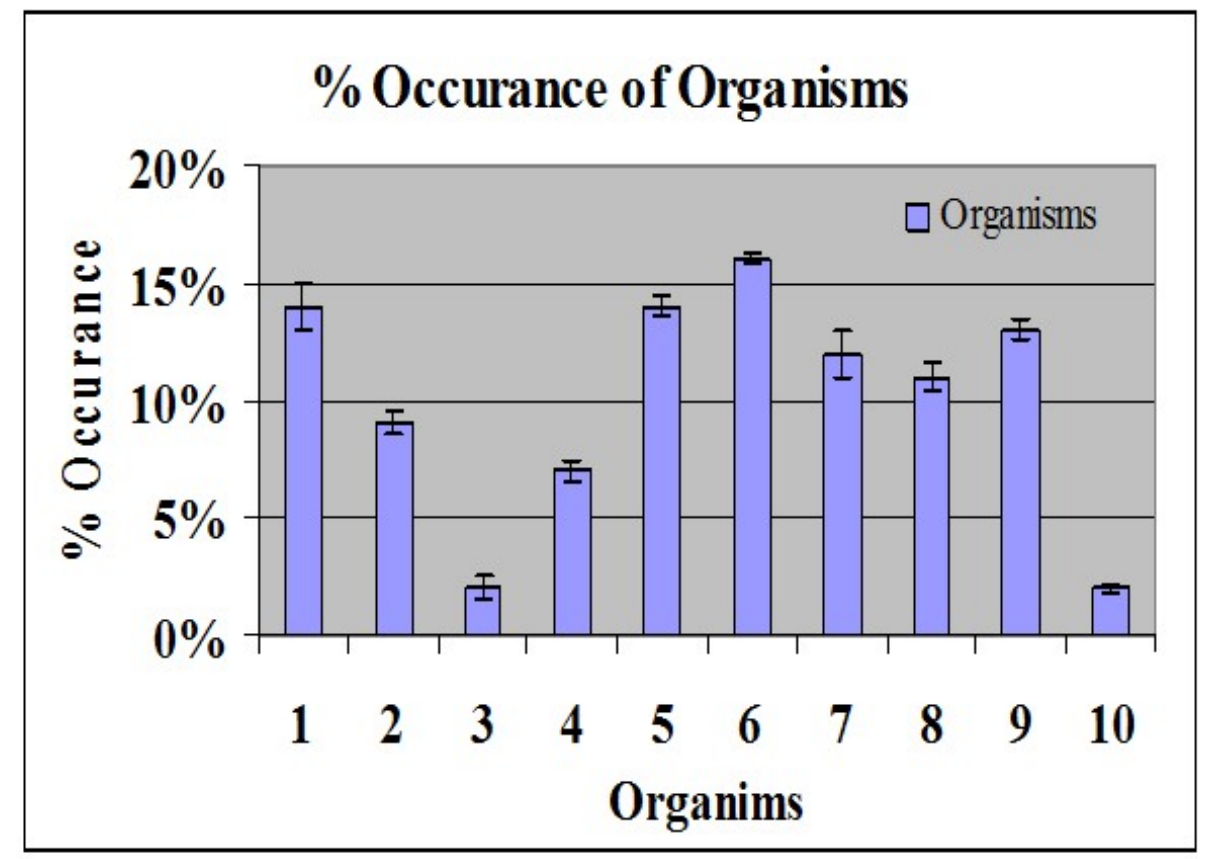

Figure 1: Graphical representation of percentage of occurence of Organisms

Polymicrobial growth was shown by samples which Antibiotic// Susceptibility Testing: The overall mainly included endotracheal aspirate, urine and pus samples. The predominant spp isolated from pediatric intensive care unit were Pseudomonas aeruginosa, Klebsiella pneumoniae, Enterococcus faecalis, sensitivity percentage to ampicillin and gentamicin was highest followed by cefotaxime and ceftriaxone. One isolate of Acinetobacter baumannii and Pseudomonas aeruginosa each isolated from blood Candida spp and Acinetobacter baumannii. Samplen showed maximum multiple resistance Occurrence of Pseudomonas aeruginosa was found to patterns. Antimicrobial Sensitivity pattern shown by be more by $95 \%$ confidence interval as compared to other organisms.

some nosocomial pathogens isolated from samples are shown below.

\begin{tabular}{|c|c|c|c|c|c|c|c|c|}
\hline Gram -ve isolate & Am & Pg & Gm & Im & $\mathbf{C b}$ & $\mathbf{C f}$ & $\mathbf{R p}$ & $\mathbf{A k}$ \\
\hline Acinetobacter baumannii 1 & $\mathrm{~S}$ & $\mathrm{~S}$ & $\mathrm{~S}$ & $\mathrm{~S}$ & $\mathrm{~S}$ & $\mathrm{R}$ & $\mathrm{S}$ & $\mathrm{S}$ \\
\hline Acinetobacter baumannii 2 & $\mathrm{R}$ & $\mathrm{R}$ & $\mathrm{R}$ & $\mathrm{S}$ & $\mathrm{R}$ & $\mathrm{S}$ & $\mathrm{R}$ & $\mathrm{S}$ \\
\hline Klebsiella pneumoniae 1 & $\mathrm{~S}$ & $\mathrm{~S}$ & $\mathrm{~S}$ & $\mathrm{~S}$ & $\mathrm{~S}$ & $\mathrm{~S}$ & $\mathrm{~S}$ & $\mathrm{~S}$ \\
\hline Klebsiella pneumoniae 2 & $\mathrm{~S}$ & $\mathrm{~S}$ & $\mathrm{R}$ & $\mathrm{S}$ & $\mathrm{S}$ & $\mathrm{S}$ & $\mathrm{R}$ & $\mathrm{S}$ \\
\hline Pseudomonas aeruginosa 1 & $\mathrm{R}$ & $\mathrm{R}$ & $\mathrm{S}$ & $\mathrm{R}$ & $\mathrm{R}$ & $\mathrm{R}$ & $\mathrm{R}$ & $\mathrm{R}$ \\
\hline Pseudomonas aeruginosa 2 & $\mathrm{R}$ & $\mathrm{S}$ & $\mathrm{S}$ & $\mathrm{R}$ & $\mathrm{S}$ & $\mathrm{S}$ & $\mathrm{R}$ & $\mathrm{S}$ \\
\hline Pseudomonas aeruginosa 3 & $\mathrm{~S}$ & $\mathrm{~S}$ & $\mathrm{~S}$ & $\mathrm{R}$ & $\mathrm{S}$ & $\mathrm{R}$ & $\mathrm{S}$ & $\mathrm{S}$ \\
\hline Escherichia coli 1 & $\mathrm{~S}$ & $\mathrm{R}$ & $\mathrm{S}$ & $\mathrm{S}$ & $\mathrm{S}$ & $\mathrm{R}$ & $\mathrm{S}$ & $\mathrm{S}$ \\
\hline Escherichia coli 2 & $\mathrm{R}$ & $\mathrm{S}$ & $\mathrm{R}$ & $\mathrm{S}$ & $\mathrm{S}$ & $\mathrm{S}$ & $\mathrm{S}$ & $\mathrm{S}$ \\
\hline
\end{tabular}




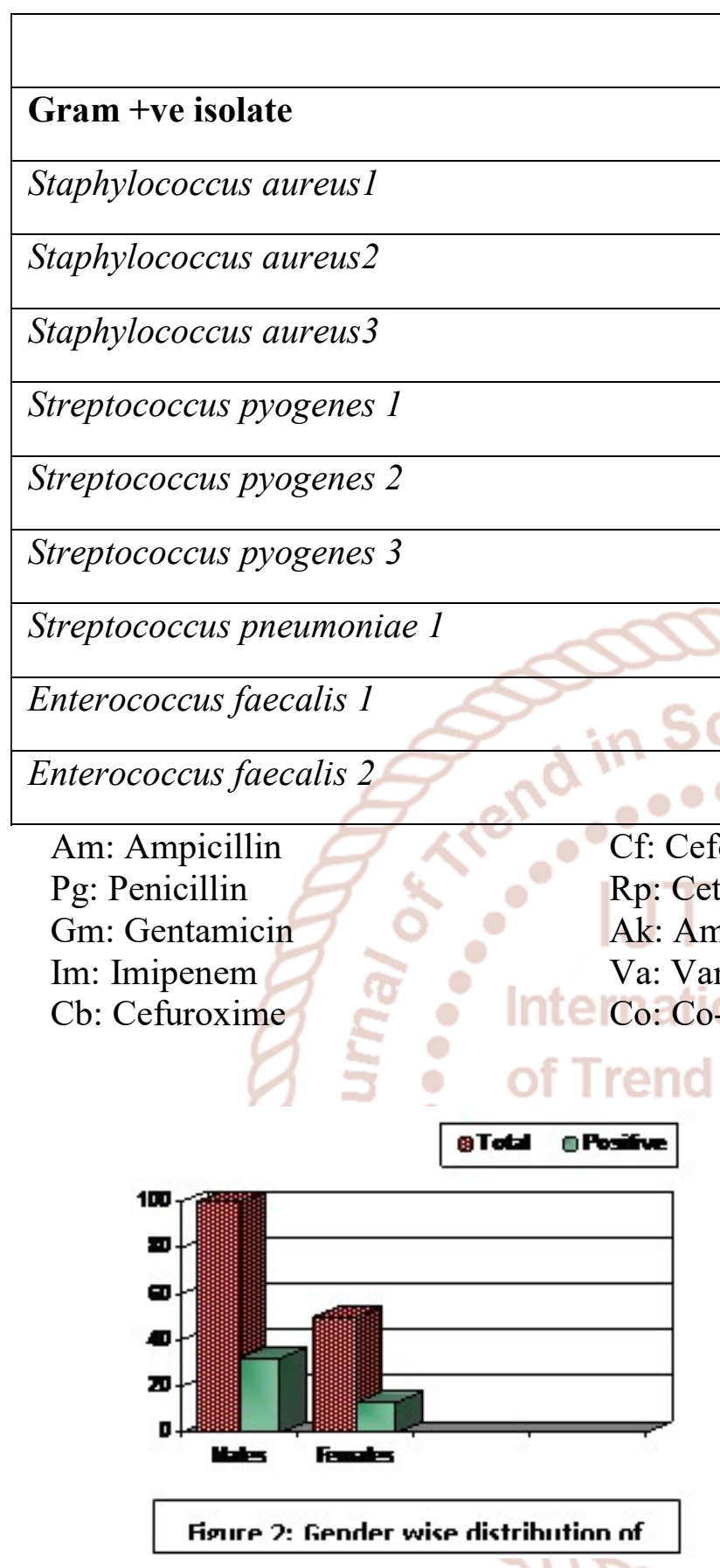

13 out of 50 female patients and 32 out of 100 male patients were found positive (Figure 2). 28 out of 98 patients within age group up to 5 yrs and 15 out of 52 patients with age group 5-12 yrs were found positive (Figure 3). Most of the infections were detected within 5 days after admission to ICU.

\section{DISCUSSION:}

The increasing rate of incidence of nosocomial infections is giving alarming signals to health care professionals. Infected or colonized patients, health care providers are the major source of nosocomial infections. Medical equipment, contaminated supplies and lack of aseptic practices also lead to the problem.

\begin{tabular}{|l|l|l|l|l|l|l|l|}
\hline Va & Pg & Co & Cd & Er & Lz & Rc & Tec \\
\hline S & R & S & R & S & S & S & S \\
\hline S & S & S & S & R & S & R & S \\
\hline S & S & R & S & R & S & R & S \\
\hline S & S & R & S & S & S & R & S \\
\hline S & R & S & S & S & S & S & R \\
\hline S & S & S & R & S & R & S & S \\
\hline S & S & S & R & S & S & R & S \\
\hline S & R & S & S & S & R & S & S \\
\hline S & R & R & R & R & R & R & S \\
\hline
\end{tabular}

Cd: Clindamycin

Er: Erythromycin

Lz: Linezolid

Rc: Ciprofloxacin

Tec: Teicoplanin

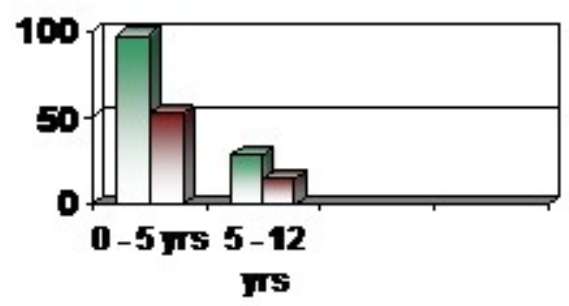

Iotral aPosive

Figure 3: Age wise distribution of patients in

ICU patients have 5-10 \% more probability of infections and PICU patients are in a state of immunocompromised conditions; which further increases due to the disorders for which they get admitted to the hospitals. B. Cao et al have documented the 'Risk Factors and clinical Outcomes of nosocomial multidrug resistant $P$. aeruginosa infections' ${ }^{[8]}$. J. S. Heal et al have documented the 'Bacterial contamination of surgical gloves by water droplets spilt after scrubbing' [16]. They have also found the hospital staff to be the major determinant of the spread of pathogens in adult ICU. Overuse of antibiotics has introduced multidrug resistant nosocomial pathogens as depicted in the current study. This is a point of concern. Endotracheal 
aspirate samples showed maximum rate of incidence of nosocomial pathogens in this study, while the major organisms found in paediatric intensive care unit were Pseudomonas aeruginosa followed by Klebsiella pneumoniae and Enterococcus faecalis. Unlike other studies however the age, sex and ICU stay did not show prominent effect in the incidence of infections.

\section{CONCLUSION:}

Nosocomial Infections need to be controlled by taking proper precautionary measures by everyone related to hospital. The immunocompromised state, the disease and medical equipments in ICU make pediatric patients more susceptible to such infections. In the present study however gender of the patient and ICU stay of the patients did not influence the incidence of nosocomial infection. It was observed in the study that the chances of acquiring such infections increase within $95 \%$ confidence level in case of in ICU stay. Appropriate preventive measures will help reducing nosocomial infections. Endotracheal aspirate samples showed maximum rate of incidence of nosocomial pathogens in our study and Pseudomonas aeruginosa showed the highest rate of occurrence. A knowledge of the organisms isolated and their antimicrobial susceptibility helps in decision regarding the antimicrobial therapy. Overuse of antibiotics should also be avoided to reduce upsurge of multidrug resistant organisms as found in present study. The future prospect of the study would involve finding of the source of infection and suggesting measures of suitable antibiotic therapy.

\section{ACKNOWLEDGMENT:}

I would like to thank Dr. Gita Nataraj, Professor, Department of Microbiology, KEM hospital, Mumbai for her kind support and guidance.

\section{REFERENCES:}

1. A. Carbonne, T. Naas, K. Blanckarert, C. Couzigou, C. Cottoen, J. L. Chagnon. (2005) 'Investigation of a nosocomial outbreak of an extended spectrum $\beta$-lactamase VEB-1 producing isolates of Acinetobacter baumannii in a hospital setting.' J. Hospital Infection Vol. 60, No.1, 1418.

2. A. F. Vicca. (1999) 'Nursing Staff worked as a determinant of Methicillin-resistant staphylococcus aureus spread in adult ICU.' J. Hospital Infection, Issue 2, Vol.43, 109-114.

3. T. Pillay, D. G. Pillay, M. Adhikari, A.W. Sturn. (1999) 'An Outbreak of neonatal infection with Acinetobacter linked to contaminated suction catheter.' J. Hospital Infection Issue 4, Vol.43, 299-304.

4. Robert J. Sherertz, Felix A. Sarubbi. (1983) 'A three year study of nosocomial infections associated with P. aeruginosa.' J. Clinical Microbiology Vol.18, 160-164.

5. S. T. Engelhart, L. Hanses, Derendorf, M. Exner, M. H. Kramer (2005) 'Prospective surveillance of health care associated infections in German nursing home residents.' J. Hospital Infection Vol. 60 No.1, 46-50.

6. Arakawa, Y., N. Shibata, K. Shibayama, H. Kurukawa, T. Yagi, H. Fujiwara, and M. Goto. (2000) ${ }^{\circ}$ Convenient test for screening metallo- $\beta$ lactamase-producing gram-negative bacteria by using thiol compounds.' J. Clin. Microbiol. 38:4043.

7. Arakawa Y, Shibata N, Shibayama K, Kurokawa H, T. Yagi, H. Fujiwara, and M. Goto. (2000) 'Convenient test for screening metallo- $\beta$ lactamase-producing gram-negative bacteria by using thiol compounds.' J. Clin. Microbiol. 38:4043.

8. Arakawa Y, Shibata N, Shibayama K, Kurokawa H, Yagi T, Fujiwara H, Goto M. (2000) 'Convenient test for screening metallo-betalactamase producing gram negative bacteria by using thiol compounds.' J. Clinical Microbiology Jan: 38(1):40-3.

9. B. Cao, H. Wang, H. Sum, Y. Zhu, M. Chen. (2004) 'Risk Factors and clinical Outcomes of nosocomial multidrug resistant $P$. aeruginosa infections.' J. Hospital Infection Issue 2, Vol.57, $112-118$.

10. C. Auriti, A. Maccalline, G. D. Liso, V. Di. Ciommo, M. P. Ronchetti, M. Orzalesi. (2003) 'Risk factors for nosocomial infections in Neonatal ICUs.' J. Hospital Infection Issue 1, Vol.53, 25-30.

11. Bauer AW, Kirby WMM, Sherris JC, Turck M. Antibiotic susceptibility testing by a standardized single disk method. Am J Clin Path 1966; 45: 493496. 
12. Clyde Thorn Sberry \& Linda K. McDougal. (1983) 'Successful use of Broth Microdilution in susceptibility tests for MRSA.' J. Clinical Microbiology, Vol.18, 1084-1091.

13. Emory TG et al. (1991) 'National Nosocomial Infections Surveillance System. Description of surveillance methods.' Am. J Infect Control, 19:19-35.

14. Emory TG, Gaynes R P. (1993) 'An overview of nosocomial infections including the role for the microbiology laboratory.' J. Clin Microbiol Rev, 6:428-442.

15. F. M. E. Wagenlehner, W. Weidner, K.G. Naber. (2005) 'Emergence of antibiotic resistance amongst hospital acquired UTIs \& pharmacokinetic or pharmacodynamic considerations.' J. Hospital Infection, Vol. 60, No.3, 191-200.

16. Gaynes R P. (1998) 'Surveillance of nosocomial infections in: Hospital infections, fourth edition. Bennet and Brachman, eds. Philadelphia, Lippincott-Raven': 65-84.

17. J. S. Heal, A. W. Blom, D. Titcomb, A. Taylor, K. Bowker and J. R. W. Hardy. Jan (2003) 'Bacterial contamination of surgical gloves by water droplets spilt after scrubbing.' J. Hospital Infection Issue 1, Vol.53, 136-139. 